\title{
REVIEW
}

\section{Golimumab: A Novel Anti-Tumor Necrosis Factor}

\author{
Maurizio Rossini - Salvatore De Vita Clodoveo Ferri - Marcello Govoni • \\ Giuseppe Paolazzi $\cdot$ Carlo Salvarani $\cdot$ Silvano Adami
}

To view enhanced content go to www.biologicstherapy-open.com

Received: September 20, 2013 / Published online: December 13, 2013

(c) The Author(s) 2013. This article is published with open access at Springerlink.com

\section{ABSTRACT}

Rheumatoid arthritis (RA), psoriatic arthritis (PsA), and ankylosing spondylitis (AS) are chronic immune-mediated rheumatic diseases that cause joint destruction and/or ankylosis, with resulting disability and diminished quality of life. Golimumab is the first human monoclonal antibody to tumor necrosis factor (TNF) administered monthly by subcutaneous

Electronic supplementary material The online version of this article (doi:10.1007/s13554-013-0012-y) contains supplementary material, which is available to authorized users.

M. Rossini ( $₫) \cdot$ S. Adami

Rheumatology Unit, University of Verona,

Policlinico GB Rossi, Piazzale Scuro, 37134 Verona, Italy

e-mail: maurizio.rossini@univr.it

S. De Vita

Rheumatology Clinic, Department of Biological and Medical Sciences, University of Udine, Udine, Italy

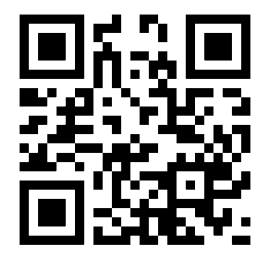

Enhanced content for this article is available on the journal web site: www.biologicstherapy-open.com injection. It is approved by the US Food and Drug Administration and by the European Medicines Agency for the treatment of RA, PsA, and AS. It is produced by a murine hybridoma cell line with innovative recombinant DNA technology, which minimizes immunogenicity of the antibody after injection. This paper reviews the main studies on the efficacy and safety of golimumab in these disease settings, illustrates the latest clinical updates, and analyzes the pharmacoeconomic aspects. Golimumab is effective in improving the physical function of patients in both the short and long term, and its

C. Ferri

Rheumatology Unit, University of Modena and Reggio Emilia School of Medicine, 41100 Modena, Italy

\section{Govoni}

Department of Medical Sciences, Section of Rheumatology, Azienda Ospedaliero-Universitaria S. Anna, University of Ferrara, V. A. Moro 8, 44124 Cona, Ferrara, Italy

G. Paolazzi

Rheumatology Unit, Ospedale Santa Chiara, Trento, Italy

C. Salvarani

Unità Operativa di Reumatologia, Azienda Ospedaliera ASMN, IRCCS, Viale Risorgimento 80, 42100 Reggio Emilia, Italy 
safety profile is in keeping with that of other anti-TNF agents; the use of golimumab is costeffective, simple, and convenient for the patient.

Keywords: Biologics; Efficacy; Golimumab; Review; Rheumatic diseases; Safety; Tumor necrosis factor

\section{INTRODUCTION}

Rheumatoid arthritis (RA), psoriatic arthritis (PsA), and ankylosing spondylitis (AS) are chronic immune-mediated rheumatic diseases that cause joint destruction and/or ankylosis, with resulting disability and diminished quality of life.

The guidelines of the European League Against Rheumatism (EULAR) on the management of RA have established that [1]:

1. treatment with disease-modifying antirheumatic drugs (DMARDs) should be initiated immediately on diagnosis so as to achieve remission or low disease activity as soon as possible, by monitoring the patient and adjusting the treatment;

2. methotrexate should be part of the first treatment strategy (in the event of contraindications or intolerance, leflunomide or sulfasalazine may be used);

3. in DMARD-naïve patients, irrespective of the addition of glucocorticoids, conventional synthetic DMARD (csDMARD) monotherapy or combination therapy of csDMARDs should be used;

4. low-dose glucocorticoids should be considered as part of the initial treatment strategy (in combination with one or more csDMARDs) for up to 6 months, but should be tapered as rapidly as clinically feasible;
5. if the treatment target is not achieved with the first DMARD strategy, in the absence of poor prognostic factors, change to another csDMARD strategy should be considered; when poor prognostic factors are present, addition of a biological DMARD (bDMARD) should be considered;

6. in patients responding insufficiently to methotrexate and/or other csDMARD strategies, with or without glucocorticoids, bDMARDs (TNF inhibitors, abatacept or tocilizumab, and, under certain circumstances, rituximab) should be commenced with methotrexate;

7. if a first bDMARD has failed, patients should be treated with another bDMARD; if a first TNF inhibitor therapy has failed, patients may receive another TNF inhibitor or a biological agent with another mode of action.

The treatment of PsA has radically changed in recent years. According to the 2012 EULAR guidelines [2], the first-line treatment in patients with a clinical diagnosis of active PsA is a non-steroidal anti-inflammatory drug (NSAID) with or without local corticosteroid injections (systemic steroids should be used with caution); by contrast, in the presence of poor prognostic markers (many swollen joints, structural damage with inflammation, elevated erythrocyte sedimentation rate/C-reactive protein (ESR/CRP) and/or clinically relevant extra-articular manifestations) treatment with a DMARD, in particular methotrexate (or sulfasalazine or leflunomide if methotrexate is contraindicated) is recommended. In cases of failure of at least one DMARD, or in patients with active enthesitis and/or dactylitis or in those with predominantly axial disease not responding to NSAIDs, the guidelines recommend treatment with a TNF- $\alpha$ inhibitor preferably with DMARD. Patients showing 
inadequate response to a TNF inhibitor may be switched to another drug of the same class [2].

In 2010, Assessments in Ankylosing Spondylitis International Society (ASAS)/ EULAR updated its guidelines for the management of patients affected by AS [3, 4]. The main treatment recommendations are as follows:

1. the cornerstone of non-pharmacological treatment of SA is patient education and regular physical exercise;

2. NSAIDs should be used as a first-line drug treatment in patients with pain and stiffness, and should be continued in persistently active symptomatic disease, after careful consideration of the cardiovascular, gastrointestinal, and renal risks; analgesics (paracetamol and opioidlike drugs) should be contemplated for residual pain whenever previous treatments have failed, are contraindicated and/or poorly tolerated;

3. local injections of corticosteroids should be considered;

4. there is no evidence of the efficacy of DMARDs in axial disease (only sulfasalazine in peripheral arthritis);

5. anti-TNF agents are recommended in patients with persistently high disease activity despite conventional treatments, without obligatory use of a DMARD before or simultaneously to the anti-TNF agent in patients with axial disease;

6. there is no evidence to support the superior efficacy of any one TNF inhibitor in axial disease and in articular/entheseal disease manifestations; switching to a second TNF inhibitor may be beneficial especially in patients with loss of response;

7. there is no evidence to support the use of biological drugs other than TNF inhibitors;
8. in patients with refractory pain or disability and radiographic evidence of structural damage, total hip replacement surgery should be considered, regardless of the patient's age [3].

\section{GOLIMUMAB CHARACTERISTICS}

\section{Unique Features of the Molecule}

Golimumab is a human monoclonal antibody specific for human TNF. It binds to both the soluble and transmembrane forms of human $\mathrm{TNF}$, giving rise to stable high-affinity complexes and preventing the binding of TNF to its receptors. It is the first anti-TNF agent with once-monthly subcutaneous (SC) administration to have been approved by the US Food and Drug Administration (FDA) and the European Medicines Agency (EMA) for the treatment of RA, PsA, and AS [5, 6].

Monoclonal antibodies were the first drugs to be produced with modern biotechnology techniques. Laboratory animals are a quick source of antibodies with high affinity and specificity, but the immunogenicity of these molecules can cause rapid clearance, reduced efficacy, and increased risk of infusion reactions in humans. By using new molecular biology techniques, mouse antibodies were reprogrammed in vitro to replace the amino acid residues with corresponding sequences of human origin [7]. Golimumab is a human monoclonal immunoglobulin G (IgG) $1 \mathrm{k}$ produced by a cell line of murine hybridomas with recombinant DNA technology, using the Medarex UltiMAb ${ }^{\circledR}$ (Medarex, Princeton, NJ, USA) transgenic mouse platform; mice engineered to express human IgG transgenes are immunized with human recombinant TNF- $\alpha$ to produce cell lines of hybridomas secreting 
human monoclonal antibodies that bind to human TNF- $\alpha$ with high affinity [8, 9]. This technique is able to produce humanized monoclonal antibodies with relatively low immunogenicity and a long half-life in vivo [7].

\section{PHARMACODYNAMICS AND PHARMACOKINETICS}

\section{Pharmacodynamics}

Golimumab is effective in modulating selective markers of inflammation and bone metabolism. A placebo-controlled dose-ranging study demonstrated improved levels of CRP and significant reductions as compared to baseline in the serum levels interleukin (IL)-6, intercellular adhesion molecules (ICAM)-1, matrix metalloproteinase (MMP)-3, and vascular endothelial growth factor (VEGF); moreover, patients with RA and AS showed a significant reduction in TNF levels and, in patients with PsA, in the levels of IL-8. The variations observed after the initial dose were maintained through week 24 . These changes in biomarkers are consistent with an improvement of the lesions and reduced inflammation and bone remodeling $[10,11]$.

A recent study by Kirkham et al. [12] evaluated the effect of golimumab on the lipid profile and inflammatory markers of cardiovascular disease in over 1,000 patients with RA enrolled in the GO-BEFORE and GO-FORWARD trials. While the serum levels of total and low-density lipoprotein (LDL) cholesterol increased slightly in patients treated with golimumab plus methotrexate, atherogenic indices remained generally stable and favorable changes were observed in LDL subfractions; additionally, the inflammatory markers for cardiovascular disease improved following treatment [12].

\section{Pharmacokinetics}

Golimumab exhibits dose-dependent pharmacokinetics after both intravenous (IV) and SC administration, with a steady-state concentration being reached within 12 weeks. With a single SC administration of $50 \mathrm{mg}$, the mean time to reach maximum serum concentration $(2.5 \mu \mathrm{g} / \mathrm{ml})$ in healthy subjects ranges from 2 to 6 days. Concomitant use of methotrexate with $50 \mathrm{mg}$ SC golimumab increased the mean steady-state trough serum concentration to approximately $0.6 \mu \mathrm{g} / \mathrm{ml}$ in patients with RA, $0.5 \mu \mathrm{g} / \mathrm{ml}$ in those with PsA, and $0.8 \mu \mathrm{g} / \mathrm{ml}$ in those with AS, equal to approximately $30 \%$ higher concentrations as compared to patients not receiving concomitant methotrexate [13].

A recent randomized open-label phase I study by Zhuang assessed the pharmacokinetics of golimumab after multiple SC (100 mg, $n=33$ ) or IV $(2 \mathrm{mg} / \mathrm{kg}, \quad n=16)$ administrations every 4 weeks for 20 weeks in 49 adult patients (median age, 57 years) with RA [14]. With SC administration, the steady state was reached after approximately 12 weeks with mean trough concentrations ranging from 1.15 to $1.24 \mu \mathrm{g} / \mathrm{ml}$. After the final IV infusion of golimumab $2 \mathrm{mg} / \mathrm{kg}$, the mean clearance was $7.5 \mathrm{ml} / \mathrm{day} / \mathrm{kg}$. The mean terminal half-life after SC and IV administrations was approximately 13 days whereas the absolute bioavailability of the SC formulation was 53\% [14]. The mean volume of distribution of golimumab was $115 \pm 19 \mathrm{ml} / \mathrm{kg}$; this means that the drug was especially present in the circulatory system, with limited extravascular distribution. Population pharmacokinetic analyses carried out on patients with RA also indicated that the concomitant use of methotrexate could reduce the apparent clearance of golimumab by $17.1 \%[13,15]$.

$\mathrm{Xu}$ et al. [16] assessed the impact of SC golimumab on the body weight and 
immunogenicity of patients with AS. The results demonstrated a tendency to greater apparent clearance of the anti-TNF agent with increasing body weight; patients with higher body weight tended to have lower trough serum golimumab concentrations at steady state. Body weight and anti-golimumab antibodies have a significant impact on golimumab clearance. The consequences of this are twofold: (a) in patients weighing over $100 \mathrm{~kg}$ and not showing adequate clinical response after 3 or 4 doses, one should consider increasing the dose to $100 \mathrm{mg}$ once a month and then, in the event of limited therapeutic benefit after 3 or 4 additional $100 \mathrm{mg}$ doses, whether or not to continue the treatment; (b) when a patient fails to respond to golimumab therapy, one should consider the possible development of anti-golimumab antibodies [16]. Finally, another phase I study did not find any significant racial difference in pharmacokinetics between two groups of patients of different race (24 Asian and 27 Caucasian) treated with golimumab [17].

\section{CLINICAL EFFICACY AND GENERAL SAFETY}

Several randomized clinical studies have evaluated the efficacy and safety of golimumab in the main rheumatic diseases affecting humans: PsA, AS, and RA (Table 1) [18-38].

\section{Psoriatic Arthritis}

The international, multicenter, randomized, placebo-controlled, double-blind, phase III trial GO-REVEAL (GOlimumab-a Randomized EValuation of safety and Efficacy in subjects with psoriatic Arthritis using a human anti-TNF monoclonal antibody) assessed the efficacy and safety of golimumab in patients naïve to biologically derived treatments, affected by active PsA despite therapy with DMARDs or NSAIDs [18-21]. The 405 adult patients with a 6 month diagnosis of moderate-to-severe active PsA ( $\geq 3$ swollen joints and $\geq 3$ tender joints), with negative rheumatoid factor and the presence of plaque psoriasis with a qualifying lesion at least $2 \mathrm{~cm}$ in diameter were randomized to one of three groups: $50 \mathrm{mg} /$ month $(n=146)$ or $100 \mathrm{mg} / \mathrm{month}$ of SC golimumab $(n=146)$ or SC placebo $(n=113)$. At week 16, patients with less than a $10 \%$ improvement from baseline in the number of swollen and tender joints entered the early escape phase, with golimumab dose escalation (from placebo to $50 \mathrm{mg}$ or from 50 to $100 \mathrm{mg}$ ). The primary endpoint was the percentage of patients with ACR20 response (American College of Rheumatology 20\% improvement criteria) at week 14 . The main secondary endpoints were: proportion of patients with ACR20 response at week 24; PASI75 (Psoriasis Area and Severity Index) response at week 14 in a subset of patients with $\geq 3 \%$ of body surface area involved by psoriasis at baseline; improvement in the NAPSI (Nail Psoriasis Severity Index) score for fingernail lesions, evaluation of dactylitis, enthesitis (MASES, Maastricht Ankylosing Spondylitis Enthesitis Score) and morning stiffness; improvement in HAQ-DI (Health Assessment Questionnaire Disability Index) scores and variations in the scores for the physical component summary (PCS) of the SF-36 (Short-Form 36) questionnaire between baseline and weeks 14 and 24. The baseline demographic characteristics of patients were well distributed across the treatment groups.

At 14 weeks, $48 \%$ of patients (140 of 292) in the combined golimumab group achieved an ACR20 response as compared with only 9\% (10 of 113) of those treated with placebo $(P<0.001$, 


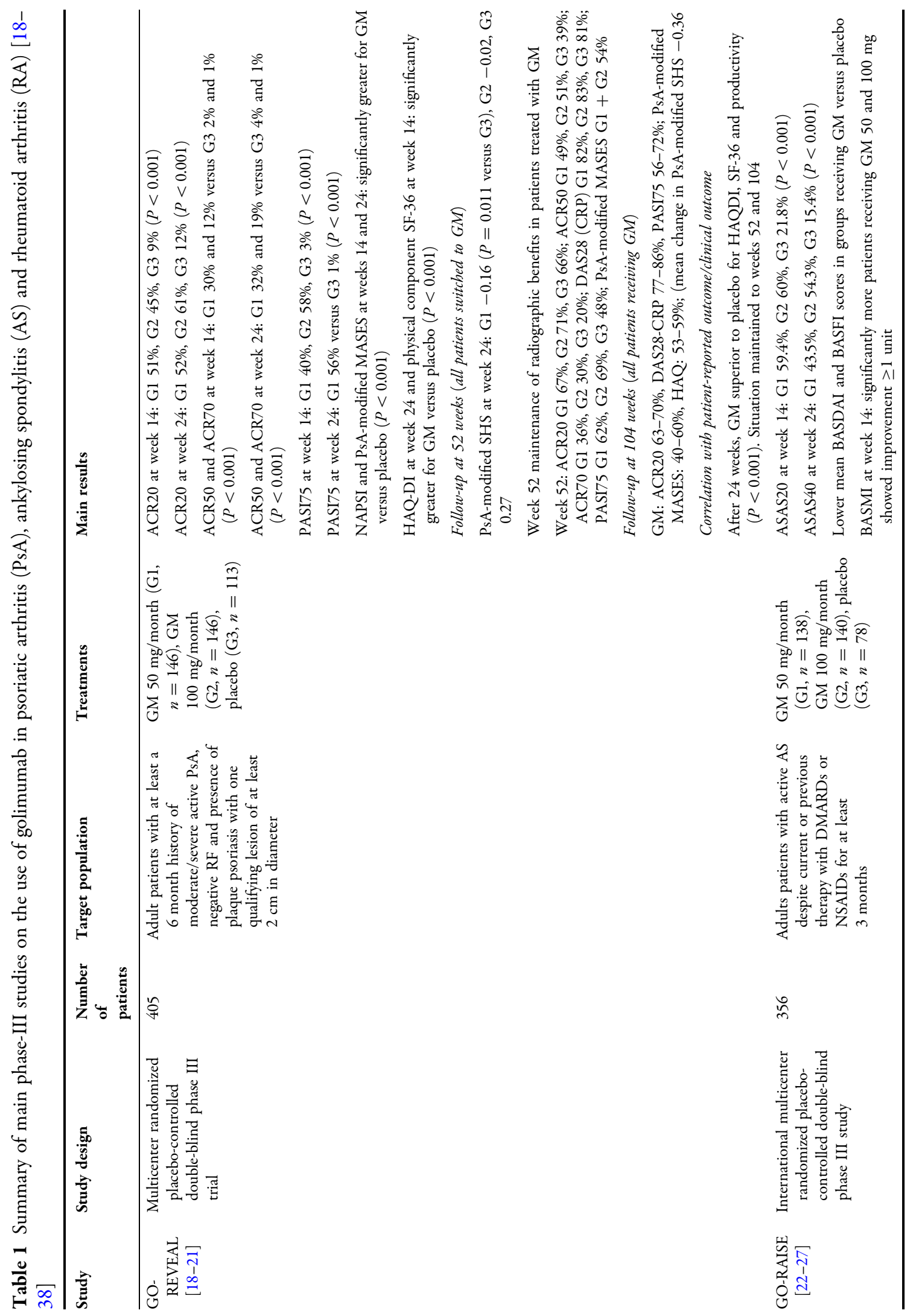




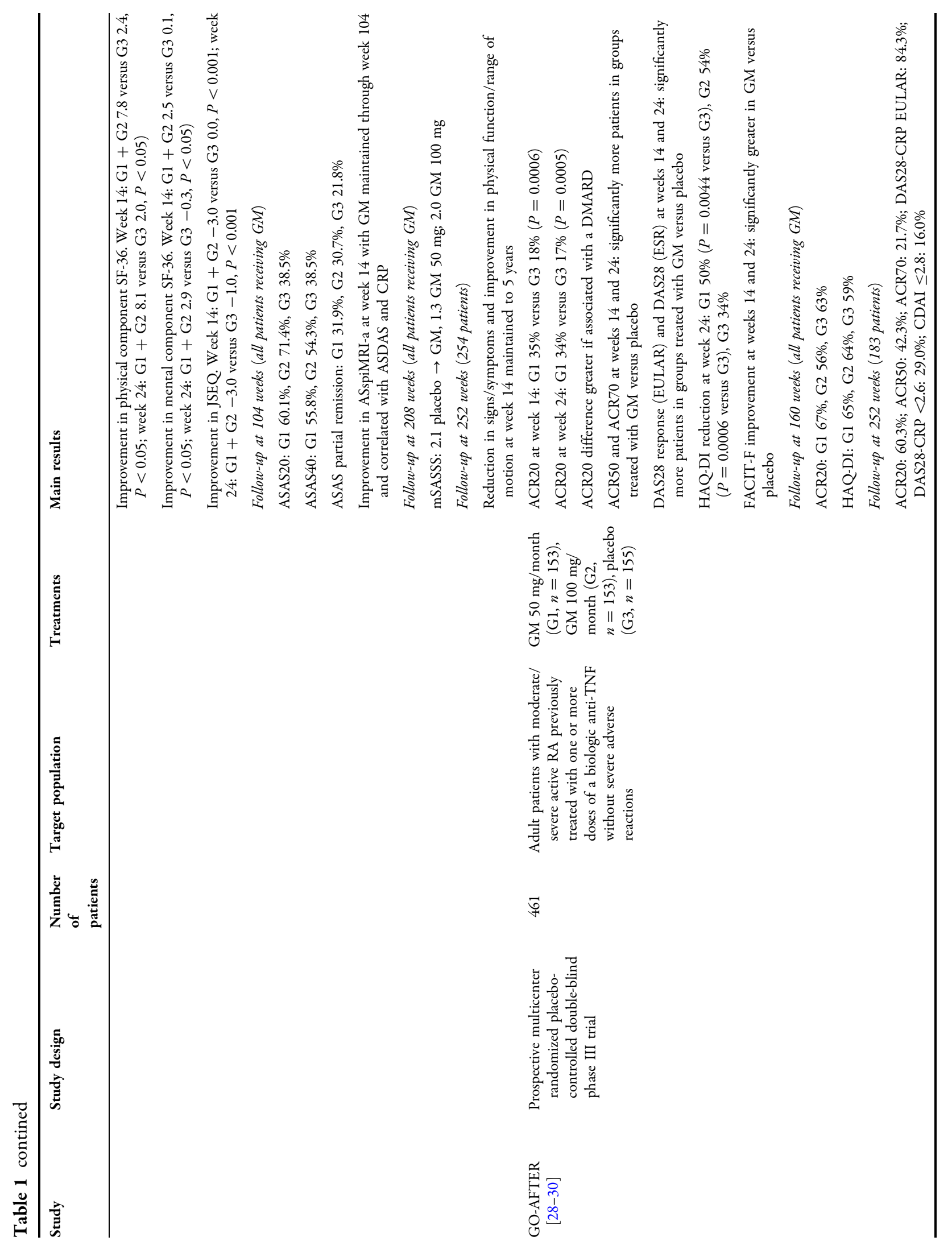




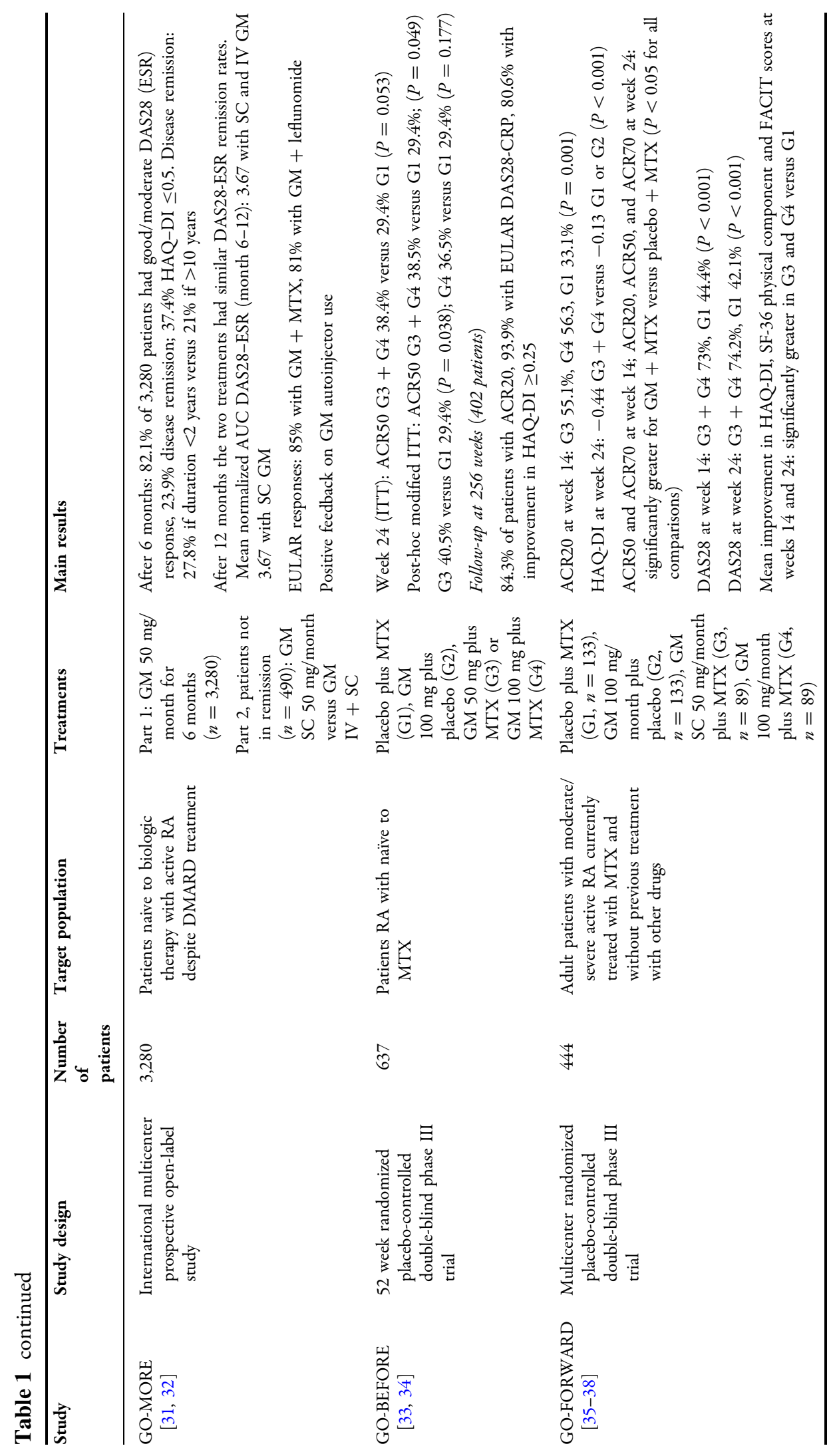




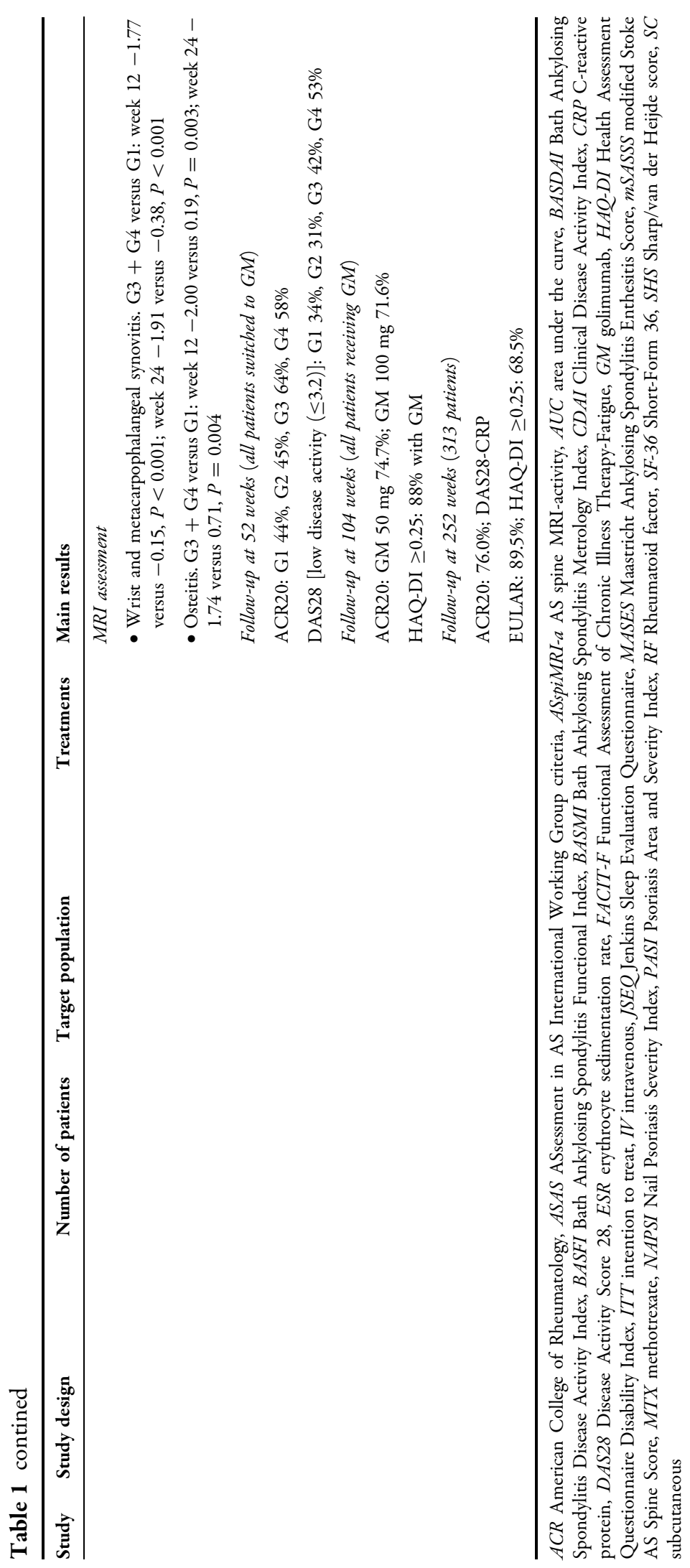


Fig. 1) [18]. Benefit was observed with both the $50 \mathrm{mg}(51 \%)$ and the $100 \mathrm{mg}$ (45\%) golimumab dose, regardless of methotrexate use; in both cases, the differences were significant as compared with placebo $(9 \%, \quad P<0.001)$. Similar results were observed at week 24 (52\%, $61 \%$, and $12 \%$, respectively; $P<0.001)$. More specifically, as compared with placebo, significantly more patients receiving golimumab $50 \mathrm{mg}$ showed ACR50 and ACR70 responses both at week 14 (30\% and $12 \%$ versus $2 \%$ and $1 \% ; P<0.001)$ and at week $24(32 \%$ and $19 \%$ versus $4 \%$ and $1 \% ; P<0.001$, Fig. 1) [18].

In the 217 patients (74\%) with psoriatic lesions involving at least $3 \%$ of the body surface area at baseline, $40 \%$ and $58 \%$ of those treated with golimumab 50 and $100 \mathrm{mg}$, respectively, had a PASI75 response at week 14 as compared with $3 \%$ of those treated with placebo $(P<0.001$ for each dose). At week $24,56 \%$ and $32 \%$ of patients receiving golimumab $50 \mathrm{mg}$ achieved PASI75 and PASI90 responses as compared with $1 \%$ and $0 \%$ of those receiving placebo $(P<0.001)$. Approximately $75 \%$ of patients included in the study had fingernail psoriasis: at weeks 14 and 24 , the median percentage change in the NAPSI score for the target fingernail was

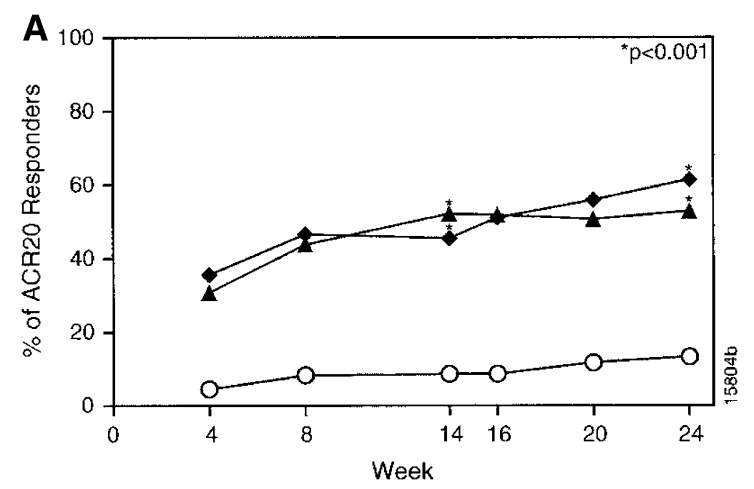

Fig. 1 GO-REVEAL study. Proportions of patients achieving at least $20 \%$ improvement according to the American College of Rheumatology criteria (ACR20 response) (a), and at least $75 \%$ improvement according to significantly greater in patients treated with golimumab as compared with those receiving placebo $(P<0.001)[18]$.

The GO-REVEAL study also evaluated two other important parameters of PsA: dactylitis, present at baseline in around one-third of patients, and enthesitis, which affected approximately two-thirds [18]. The median percentage change from baseline to weeks 14 and 24 in dactylitis scores was greater for patients in the golimumab groups as compared with those in the placebo group (the difference was not statistically significant). By contrast, golimumab treatment significantly improved both enthesitis (number of patients and MASES changes) and morning stiffness at weeks 14 and 24. Finally, patients treated with golimumab showed a significant improvement $(P<0.001)$ in the HAQ-DI score at 24 weeks and in the physical component of the SF-36 questionnaire at 14 weeks, as compared with the placebo group. Golimumab was generally well tolerated, with a safety profile consistent with that of other anti-TNF agents: the most frequent adverse reactions were nasopharyngitis and upper respiratory tract infection (especially with the $100 \mathrm{mg}$ dosage) [18].

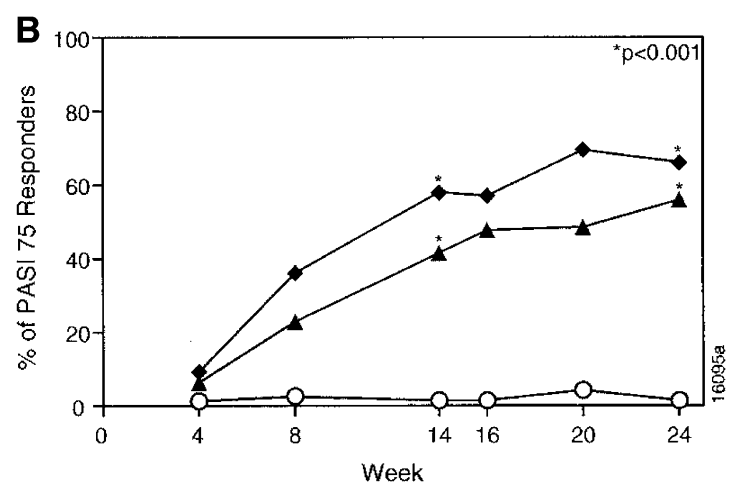

the Psoriasis Area and Severity Index (PASI 75 response) through week 24 (b) (adapted with permission from Kavanaugh et al. [18]). Open-circle placebo, filled-diamond golimumab $100 \mathrm{mg}$, filled-triangle golimumab $50 \mathrm{mg}$ 
The results of the 1- and 2-year follow-up of the GO-REVEAL study were published in 2012 $[19,20]$. At 24 weeks, patients in the placebo group who did not enter the early escape phase crossed over to golimumab $50 \mathrm{mg}$ : therefore, all patients received treatment with golimumab $50 \mathrm{mg}$ or $100 \mathrm{mg}$ during the follow-up period. The primary endpoint was the change from baseline in the radiographic PsA-modified Sharp/van der Heijde score (SHS) of the hands and feet, as assessed by two independent radiologists, and clinical response during longterm treatment with golimumab.

At 52 weeks, 360 of the 405 initial patients (89\%) were still participating in the study and 358 (88\%) continued treatment. At week 24 , the mean change from baseline of the PsA-modified SHS indicated significantly less progression in patients receiving golimumab $50 \mathrm{mg}(-0.16$, $P=0.011)$ as compared with placebo $(0.27)$, as did that of the combined golimumab groups $(-0.09, \quad P=0.015)$, whereas the difference between golimumab $100 \mathrm{mg}(-0.02)$ and placebo did not reach statistical significance. Even the secondary radiographic analyses performed at week 24 confirmed inhibition of structural damage (progression of bone erosion or new erosions) in patients treated with golimumab, particularly in those receiving golimumab plus methotrexate. The radiographic findings at week 52 showed persistence of radiographic benefit in patients treated with golimumab, and an improvement in the overall PsA-modified SHS in patients who switched from placebo to active treatment at week 24. The clinical efficacy of golimumab observed at week 24 was maintained through week 52: ACR20 response in 66\%, 67\%, and $71 \%$ of cases; ACR50 response in 39\%, $49 \%$, and $51 \%$ of cases; ACR70 response in 20\%, 36\%, and $30 \%$ of cases; DAS28-CRP (Disease Activity Score 28 and C-reactive protein) in $81 \%, 82 \%$, and
$83 \%$ of cases; PASI75 in $48 \%, 62 \%$ and $69 \%$ of cases initially treated with placebo, golimumab 50 and $100 \mathrm{mg}$, respectively. The frequency and type of adverse events were similar to those recorded at week $24[19,20]$.

A subanalysis of these data at 52 weeks focused on two typical symptoms of PsA: enthesitis and dactylitis. At week 52, the improvement seen in patients randomized to receive golimumab $50 \mathrm{mg}$ and golimumab $100 \mathrm{mg}$ was maintained (mean improvements of $54 \%$ for the PsA-modified MASES and $77 \%$ for the dactylitis score). Even the patients with enthesitis/dactylitis at baseline initially randomized to the placebo groups and switched to the active treatment group had a clinically meaningful benefit (39\% improvement in the PsA-modified MASES, 57\% in the dactylitis score) [19].

The same patients were re-evaluated after 2 years of follow-up. Long-term treatment with golimumab is efficacious in maintaining clinical response (ACR20 63-70\%, DAS28-CRP 77-86\%, PASI75 56-72\%; 67-75\% improvement in dactylitis score; 40-60\% improvement in PsAmodified MASES; $53-59 \%$ improvement in HAQ-DI) and inhibiting radiographic progression of erosions (mean change in the PsA-modified SHS in patients receiving golimumab, -0.36), without significant differences between the two drug dosages (50 and $100 \mathrm{mg}$ ). No new adverse events were recorded in the 2 years of follow-up or any cases of active tuberculosis. Long-term treatment with golimumab at either dosage (50 mg or $100 \mathrm{mg} / \mathrm{month}$ ) results in a significant and prolonged clinical and radiographic improvement as compared with placebo in patients with active PsA. The longterm safety profile of golimumab is consistent with that of the other anti-TNF agents used to treat this disease [20]. 
A recently published analysis investigated correlations between clinical outcome and the reported outcomes of patients enrolled in the GO-REVEAL study (based on questionnaires on physical function, quality of life, mental component and productivity). At 24 weeks, golimumab-treated patients had a significant mean improvement in HAQ-DI (0.36), SF-36 (PCS 7.83, MCS 3.84) and productivity score (2.24) as compared with the placebo group (0.01, 0.67 and -0.60 , respectively; $P<0.001$ for all comparisons). Moreover, a greater proportion of golimumab-treated patients achieved clinically relevant improvements in the HAQ-DI $(\geq 0.30)$ and SF-36 $(\geq 5)$ scores at week $24 \quad(P<0.05)$ as compared with the placebo group; improvements in the DAS28CRP scores also correlated significantly, albeit moderately, with improvements in HAQ-DI, SF36 PCS, and productivity. The improvements in these parameters were similar across all groups at the assessments performed at weeks 52 and 104, after the switch from placebo to golimumab [21].

\section{Ankylosing Spondylitis}

The international multicenter, randomized, double-blind, placebo-controlled, phase III trial GO-RAISE [GOlimumab-a Randomized Study in Ankylosing Spondylitis Subjects of a Novel anti-TNF mAB Injection (SC) Given Every Four Weeks] evaluated the efficacy and safety of golimumab in 356 adults patients naïve to biologic therapy, with a diagnosis of active AS [BASDAI (Bath Ankylosing Spondylitis Disease Activity Index) $\geq 4$ and a spinal pain score $\geq 4$ on a $0-10$ visual analogue scale (VAS)] despite current or previous therapy with DMARDs or NSAIDs for at least 3 months [22-27]. The patients were randomized to one of three groups: $50 \mathrm{mg} / \mathrm{month}$ SC golimumab $(n=138), \quad 100 \mathrm{mg} / \mathrm{month} \quad \mathrm{SC}$ golimumab $(n=140)$, or placebo $(n=78)$. The primary endpoint was the proportion of patients with an ASAS20 (ASsessment in AS International Working Group criteria) response at week 14 . Secondary endpoints were an ASAS20 response at week 24, ASAS40 response, the BASDAI for disease activity, VAS score of back pain and night pain, the patient's global assessment, the BASFI (Bath Ankylosing Spondylitis Functional Index) for physical function, the BASMI (Bath Ankylosing Spondylitis Metrology Index) for range of motion, the SF-36 Health Survey for quality of life, and the JSEQ (Jenkins Sleep Evaluation Questionnaire) for sleep disturbance. The patients' demographic characteristics were generally well balanced across treatment groups.

The primary endpoint was achieved: $59.4 \%$ of patients treated with golimumab $50 \mathrm{mg}$ and $60.0 \%$ of those treated with $100 \mathrm{mg}$ attained an ASAS20 response at week 14 as compared with $21.8 \%$ of the placebo group $(P<0.001)$. Moreover, $43.5 \%, \quad 54.3 \%$, and $15.4 \%$ of patients treated with golimumab 50 and $100 \mathrm{mg}$ and with placebo, respectively, achieved an ASAS40 response at week 24 [22].

On completion of treatment, the mean BASDAI and BASFI scores were lower in the groups treated with golimumab as compared with those who received the placebo. As for the BASMI scores, a significantly greater number of patients treated with golimumab 50 and $100 \mathrm{mg}$ showed an improvement from baseline $\geq 1$ unit at week 14 [22]. At week 16, 77.3\% of patients receiving golimumab and $74.0 \%$ of those receiving placebo had had $\geq 1$ adverse event, with similar proportions in the two golimumab groups (50 mg, 79.0\%; $100 \mathrm{mg}, 75.7 \%$ ). On completion of the study (week 24), these percentages were $85.6 \%$ and $79.9 \%$, respectively [22]. 
The overall scores for the physical and mental components of the SF-36 improved significantly $(P<0.05)$ from baseline to weeks 14 and 24 in all golimumab-treated patients. The same patients also showed a significant median improvement from baseline in the JSEQ score at both week 14 and week 24 (both $P<0.001$ ) [23].

Wagner et al. [39] attempted to identify the serum biomarkers modulated by golimumab treatment and associated with a clinical response in 100 patients with AS enrolled in the GO-RAISE trial. Golimumab treatment significantly reduced many serum proteins, including acute-phase reactants (CRP, haptoglobin, amyloid P), complement markers (complement 3), hematological factors (ferritin), inflammatory markers (chemokine ligand 5, epithelial neutrophil-activating protein 78, ICAM-1, macrophage antiinflammatory protein $1 \beta$, MMP-3, TIMP-1, TNF receptor II), metabolic markers (plasminogen activator inhibitor-1) and other markers (thyroxin-binding globulin, sex hormonebinding globulin, VEGF), at both 4 and 14 weeks as compared with placebo. Logistic regression analysis showed that the association of 2 or 3 biomarkers (insulin, leptin, immunoglobulin $\mathrm{M}$, VEGF) was more predictive of clinical outcome as compared with $\mathrm{C}$ reactive protein (CPR) alone. Golimumab is able to modulate acute-phase reactants and inflammatory markers in patients with AS [39].

Braun et al. [25] published the results of the long-term follow-up (104 weeks) of the GO-RAISE trial. At week 104, 38.5\%, 60.1\%, and $71.4 \%$ of the patients initially treated with placebo, golimumab 50 and $100 \mathrm{mg}$, respectively, showed an ASAS20 response; $38.5 \%, 55.8 \%$, and $54.3 \%$ an ASAS40 response, and $21.8 \%, 31.9 \%$, and $30.7 \%$ were in ASAS partial remission. Additionally, the mean
BASDAI and BASFI scores were lower than 3 in all treatment groups. Golimumab safety at week 104 was similar to that observed at week 24 and consistent with that of other anti-TNF agents [25].

The 4- and 5-year updates of the GO-RAISE trial confirm the findings observed at year 2 [27]. In particular, the assessment at year 4 considered the radiographic progression of disease. At week 208, after treatment with golimumab for 3.5-4 years, the change (mean $\pm S E$ ) in the modified Stoke AS Spine Score (mSASSS) was $2.1 \pm 5.2$ in the patients switched from placebo to golimumab, and $1.3 \pm 4.1$ and $2.0 \pm 5.6$ in those treated with golimumab 50 and $100 \mathrm{mg}$, respectively. Less than one-third of patients had a definitive change as compared to the baseline mSASSS $(>2)$. At week 208, less radiographic progression was noted in patients without syndesmophytes at baseline (0.2 versus 2.8 in patients with $\geq 1$ syndesmophytes; $\quad P<0.0001)$ and lower baseline CPR (0.9 versus 2.9 with CRP $\leq 1.5 \mathrm{mg} / \mathrm{dl}$ and $>1.5 \mathrm{mg} / \mathrm{dl}$, respectively; $P=0.0004)$ Radiographic progression remained stable at the assessments at year 2 and 4 , suggesting no acceleration of new bone formation over time [27].

Of the 356 patients included in the study, 254 continued treatment through week 252 (5 years). The reduction in signs and symptoms of AS and the improvement in physical function and range of motion seen at week 14 were maintained to year 5. Severe adverse events were reported by $17.1 \%$ of patients receiving $50 \mathrm{mg}$ golimumab and $22.0 \%$ of all patients receiving golimumab [24].

Finally, Braun also investigated the effect of golimumab on spinal inflammation seen on magnetic resonance imaging (MRI) in a subset of 98 AS patients of the GO-RAISE trial who underwent complete serial MRI (baseline, week 14 and week 104) [26]. The MRI images were 
read by two independent radiologists using the SA spine MRI-activity (ASspiMRI-a) score. The baseline ASspiMRI-a scores were lower in the group treated with golimumab $100 \mathrm{mg}$ (3.5) as compared with those in the placebo group (6.8) and the golimumab $50 \mathrm{mg}$ group (7.8). The improvement in the ASspiMRI-a score at week 14 was significantly greater in patients treated with golimumab $50 \mathrm{mg}$ as compared to those in the placebo group ( -3.5 versus $-0.5, P=0.047$ ), whereas the difference between golimumab $100 \mathrm{mg}$ and placebo was not statistically significant $(-1.5$ versus $-0.5, P=0.14)$. After adjustment for disparities in the baseline ASspiMRI-a scores, the improvement versus placebo became significant both for the $50 \mathrm{mg}$ $(P=0.011)$ and for the $100 \mathrm{mg} \quad(P=0.002)$ golimumab groups. The improvements in the ASspiMRI-a score after 14 weeks of golimumab therapy were maintained to week 104 and correlated only with the disease activity score (ASDAS) and CRP, but not with the other clinical outcomes [26].

\section{Rheumatoid Arthritis}

The prospective, multicenter, international, randomized, double-blind, placebo-controlled, phase III trial GO-AFTER (GOlimumab After Former anti-TNF Therapy Evaluated in Rheumatoid Arthritis) investigated the efficacy and safety of golimumab in patients with active RA who had been treated with at least one TNF inhibitor [28-30]. The study population consisted of 461 adult patients with moderateto-severe active RA, who had received (at least 8 to 12 weeks prior to administration of the study drug) one or more doses of a biological anti-TNF agent (infliximab, etanercept, and/or adalimumab) without reporting severe adverse reactions. The patients had discontinued the anti-TNF- $\alpha$ agent because of ineffectiveness
( $n=269,58 \%$ of patients) or intolerance and poor accessibility of the drug $(n=246,53 \%$ of patients). The patients were randomized to three study arms: $50 \mathrm{mg} / \mathrm{month}$ of SC golimumab $(n=153), 100 \mathrm{mg} / \mathrm{month}$ of SC golimumab $(n=153)$ or SC placebo $(n=155)$. At week 16, patients who had less than a $20 \%$ improvement in symptoms were switched from placebo to $50 \mathrm{mg}$ golimumab, or from 50 to $100 \mathrm{mg}$ golimumab. The primary endpoint was the proportion of patients with an ACR20 response at week 14, whereas the main secondary endpoints were ACR20 response at week 24, ACR50 and ARC70 responses at weeks 14 and 24, DAS28 (CRP) response at weeks 14 and 24, and improvement in the HAQ-DI score and fatigue [assessed with the Functional Assessment of Chronic Illness Therapy-Fatigue (FACIT-F) questionnaire] at weeks 14 and 24.

The baseline demographic characteristics of all groups were similar in terms of number of swollen and tender joints, HAQ-DI score, CRP and ESR, DAS28 score with ESR, proportion of patients positive for anti-CCP antibodies or rheumatoid factor, and of patients treated with methotrexate. Moreover, prior to recruitment $25 \%(n=115)$ of patients had been treated with two anti-TNF agents and 9\% $(n=43)$ with three agents [28].

The analysis of the primary endpoint at week 14 showed that significantly more patients treated with golimumab achieved an ACR20 response as compared with the placebo group. More specifically, 35\% of patients treated with golimumab $50 \mathrm{mg}$ achieved the primary endpoint of ACR20 response at week 14 as compared with $18 \%$ of patients who received placebo $(P=0.0006)$. A similar situation was seen at week $24: 34 \%$ of patients who received golimumab $50 \mathrm{mg}$ attained an ACR20 response as compared with $17 \%$ of those treated with placebo $(P=0.0005)$. The proportions of 
patients achieving ACR50 and ACR70 responses were also significantly higher among the golimumab-treated groups, both at weeks 14 and 24. The difference between the percentage of patients achieving an ACR20 response after receiving golimumab or placebo was greater when a concomitant DMARD was associated. Significantly more patients treated with golimumab achieved an ACR20 response than did those on placebo, even when the subject had received prior treatment with one or two antiTNF agents, and the response was independent of the reason for discontinuation of the anti-TNF (ineffectiveness or intolerance). Finally, the difference between the combined golimumab groups and the placebo group was significant as of the first administration of the drug. At weeks 14 and 24, significantly more patients treated with golimumab achieved a DAS28 (EULAR) response and a DAS28 (ESR) remission as compared to those who received placebo. In particular, at week 14, administration of golimumab $50 \mathrm{mg}$ resulted in a better DAS28 response and DAS28 remission as compared with placebo (49\% versus $27 \% ; P=0.0001 ; 8 \%$ versus $1 \%, P=0.0009)$. At week 24 , similar results were observed for DAS28 response and DAS28 remission. Finally, at week 24 , only $34 \%$ $(n=53)$ of patients treated with placebo had a minimum clinically relevant reduction in HAQDI, as compared with $50 \%(n=77)$ of those receiving golimumab $50 \mathrm{mg}(P=0.0044)$ and $54 \% \quad(n=82)$ of those receiving $100 \mathrm{mg}$ $(P=0.0006)$. The improvement from baseline to weeks 14 and 24 in FACIT-F was significantly greater for golimumab than for placebo. At week 16 , adverse events were reported in $70 \%$ of patients receiving placebo, $61 \%$ of those treated with golimumab $50 \mathrm{mg}$ and $74 \%$ of those treated with golimumab $100 \mathrm{mg}$, whereas the percentages of severe adverse events were $7 \%$, $3 \%$, and 5\%, respectively [28].
An important aspect of the management of RA cases that are difficult to treat concerns maintaining the response over time. Smolen's group recently published the results of the longterm extension (160 weeks) of the GO-AFTER trial [29]. After week 24, the patients receiving placebo crossed over to golimumab $50 \mathrm{mg}$, whereas those receiving $50 \mathrm{mg}$ could either continue with this dose or switch to golimumab $100 \mathrm{mg}$. A total of 236 patients (51\%) continued treatment until week 160. From week 24 to week 100, the ACR20, DAS28 and HAQ-DI responses were maintained in $70-73 \%, 78-84 \%$, and $75-81 \%$ of responders, respectively. At week 160, an ACR20 response was observed in $63 \%$ of patients initially treated with placebo, in $67 \%$ of those treated with golimumab $50 \mathrm{mg}$, and in $57 \%$ of those treated with golimumab $100 \mathrm{mg}$; improvements in the HAQ-DI score were seen in 59\%, 65\%, and 64\% of cases, respectively. Moreover, the addition or dose escalation of golimumab enhanced the clinical response. At week 160, the incidences of adverse events per 100 patient-years in subjects treated with golimumab 50 and $100 \mathrm{mg}$ were 4.70 and 8.07 for severe infections, 0.95 and 2.04 for malignancy, and 0.00 and 0.62 for death, respectively. In patients with active RA previously treated with an anti-TNF agent, prolonged use of golimumab 50 and $100 \mathrm{mg} /$ month enabled the improvement in signs/ symptoms and physical function to be maintained in approximately $57-67 \%$ of patients who continued the treatment [29].

The 5-year results of the 183 patients who continued treatment through week 252 in the GOAFTER trial were recently presented at the EULAR 2013 conference [30]. The analysis of the patients with available data showed an ACR20 response in $60.3 \%$ of cases, an ACR50 response in $42.3 \%$, an ACR70 response in $21.7 \%$, and a DAS28-CRP EULAR response in $84.3 \%$; moreover, $29.0 \%$ of 
patients had a DAS28-CRP $<2.6$ and $16.0 \%$ a Clinical Disease Activity Index $(\mathrm{CDAI}) \leq 2.8$. The most common adverse events were upper respiratory tract infections $(27.1 \%)$, sinusitis (17.1\%), and nasopharyngitis (16.9\%). The efficacy of golimumab was maintained to 5 years in patients with refractory RA who continued treatment, and its long-term safety is consistent with that of other anti-TNF- $\alpha$ agents [30].

The prospective, international participating countries), multicenter centers), open-label trial GO-MORE investigated the efficacy of SC or IV golimumab as an add-on to a DMARD in adult patients ( $\geq 18$ years) naïve to biological drugs and affected by RA that was inadequately controlled by the DMARD (DAS28$\mathrm{ESR} \geq 3.2$ ) [31].

In part 1 of the study, the patients were treated with golimumab $50 \mathrm{mg}$ SC (delivered via an automatic injector) once a month for 6 months. The primary endpoint was a good/ moderate EULAR response (DAS28-ESR) after 6 months of treatment; moreover the study also evaluated whether the response to golimumab could be influenced by variables such as methotrexate dosage, concomitant DMARD, steroid use or the number of failed DMARDs. In part 2, patients with a good or moderate response but not in remission (DAS28-ESR $<2.6)$ at 6 months were randomly allocated to one of two groups: golimumab $50 \mathrm{mg}$ SC once monthly or combined IV and SC golimumab, with assessment of DAS28-ESR remission at 12 months. The primary endpoint of part 2 of the study was remission at the beginning of month 11 and the end of month 12 [31].

A total of 3,366 patients were enrolled; $91.7 \%$ of them completed part 1 of the study. At 6 months, $82.1 \%$ of the 3,280 patients included in part 1 (83\% women; mean age, 52.3 years; mean disease duration, 7.6 years; mean DAS28-ESR, 5.97; concomitant methotrexate, 81\%; all with prior DMARD therapy) showed a good (36\%) or moderate (46.1\%) DAS28-ESR response, achieved after only 2 months of treatment. Analysis of the EULAR responses by the number of previous failed DMARDs or other concomitant variables (methotrexate dose, DMARD type or corticosteroid use) did not show statistically significant differences: approximately $80 \%$ of patients in all subgroups had a good/moderate EULAR response (Fig. 2) [31].

The rates of good-to-moderate EULAR response, low DAS-ESR disease activity, and remission increased steadily during the treatment period; at 6 months, $23.9 \%$ of patients also achieved disease remission. Even the HAQ-DI scores improved after golimumab treatment: either no functional change or only a minimal change (HAQ-DI $\leq 0.5)$ was attained in $37.4 \%$ of cases after 6 months. The patients with short duration of disease were more likely to achieve remission: $27.8 \%$ for disease duration less than 2 years versus $21 \%$ if more than 10 years. In part 2 of the study, 490 patients not in remission could be assessed for efficacy: at 12 months the two SC and IV + SC treatments resulted in similar DAS28-ESR remission rates. The mean normalized AUC (area under the curve) for DAS28-ESR from month 6 through 12 was similar in the two groups: 3.67 in the group treated with IV + SC golimumab and 3.67 in the group receiving only SC golimumab $(P=0.931)$. The most common treatment-related adverse events observed in part 1 were nasopharyngitis (4.8\%), urinary tract infections (3.3\%), headache $(3.2 \%)$, diarrhea $(2.7 \%)$, and bronchitis $(2.4 \%)$. The overall incidence of these effects in part 2 was similar to that recorded in part 1 in all treatment groups. The addition of golimumab proved to be effective in treating active RA despite DMARD treatment. 

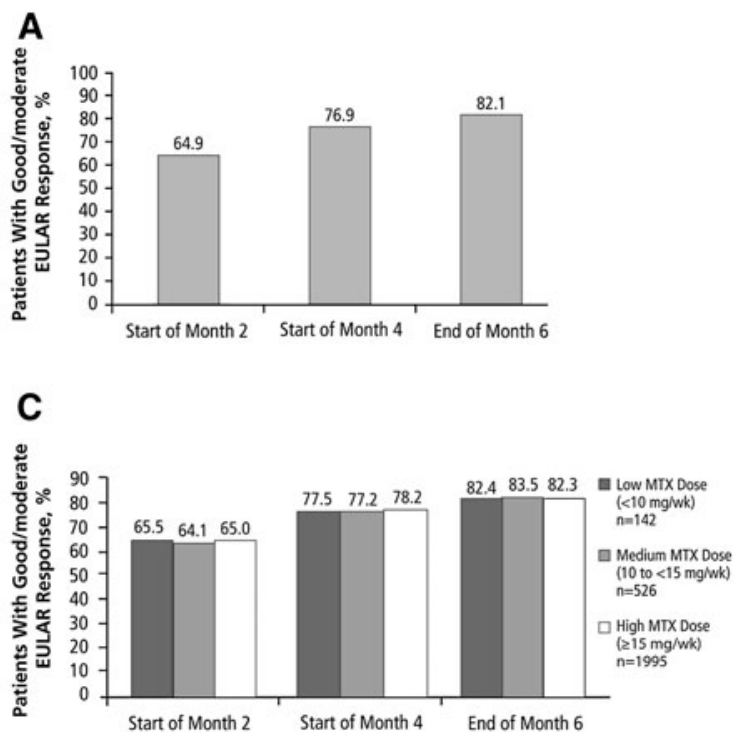

Fig. 2 GO-MORE study. Response to golimumab treatment over 6 months in part 1: percentage of patients with good or moderate EULAR response (a), percentage of patients who achieved good or moderate EULAR DAS28 response by the number of previously failed DMARDs (b), percentage of patients who achieved good or moderate EULAR DAS28 response by concomitant methotrexate

Combination of the two golimumab formulations failed to yield any additional benefit compared to the SC formulation alone [31].

At the recent EULAR 2013 conference further analyses of the GO-MORE trial were presented [32]. Wollenhaupt et al. [32] evaluated the efficacy and safety of golimumab added to either methotrexate $(81.2 \%)$ or leflunomide (9.3\%). After 6 months the results were similar; the percentage of EULAR response was $85 \%$ for the combination with methotrexate and $81 \%$ for the combination with leflunomide [32].

Analyzing the patients' baseline characteristics and the clinical efficacy according to the geographic region in which the GO-MORE trial was conducted, Durez found considerable variations in these parameters [40]. Firstly, a high EULAR disease activity at baseline
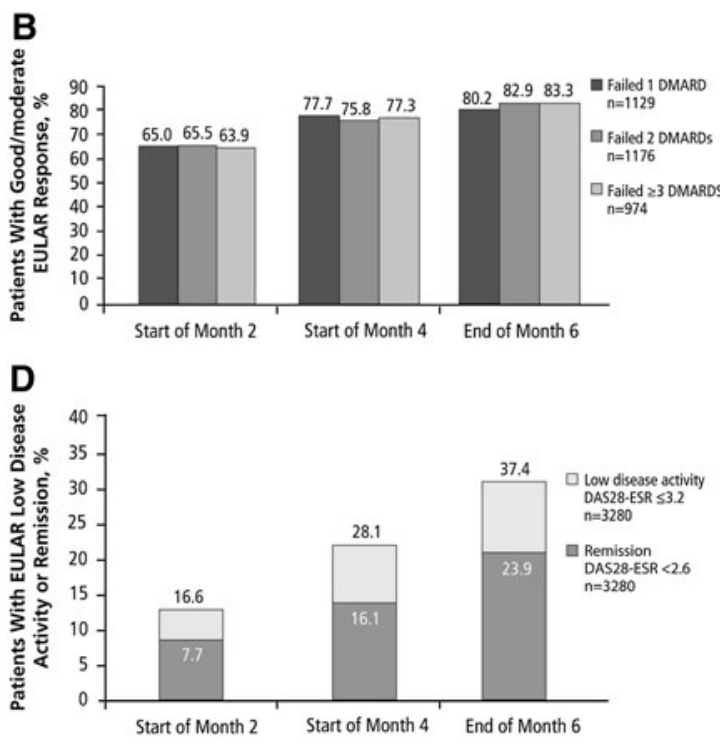

dose (c), and percentage of patients who achieved low disease activity or remission (d). DAS28 28-joint disease activity score, $D M A R D$ disease-modifying anti-rheumatic drug, ESR erythrocyte sedimentation rate, EULAR European League Against Rheumatism, GLM golimumab, $M T X$ methotrexate (adapted with permission from Combe et al. [31])

was predominant in South Africa, Asia, and Latin America, whereas disease duration was longer in Latin America and South Africa. As a consequence, the remission rates varied considerably depending on the geographic region, with the lower remission rates being generally observed in the regions with higher disease activity at baseline and longer disease duration [40].

Finally, add-on golimumab in this population of patients with active RA despite DMARD therapy allowed for a good Comprehensive Disease Control (combined endpoint of clinical remission, low disease activity and important patient outcomes such as physical function and pain reduction) [41].

The 52-week, randomized, placebocontrolled, double-blind, phase III trial GOBEFORE (Golimumab Before Employing 
Methotrexate as the First-Line Option in the Treatment of Rheumatoid Arthritis of Early Onset), followed by a 5-year extension, evaluated 637 RA patients naïve to methotrexate, randomly allocated to one of the four groups: placebo plus methotrexate (group 1), golimumab $100 \mathrm{mg}$ plus placebo (group 2), golimumab $50 \mathrm{mg}$ plus methotrexate (group 3), or golimumab $100 \mathrm{mg}$ plus methotrexate (group 4) $[33,34]$. The primary endpoint was the difference in ACR50 response at week 24 between groups 3 and 4 combined versus group 1 and a pairwise comparison between group 3 or group 4 versus group 1.

Intention-to-treat (ITT) analysis of the ACR50 response at week 24 did not show any significant difference between the combined group and group 1 (38.4\% versus 29.4\%; $P=0.053)$, whereas a modified post-hoc ITT analysis (which excluded three patients who were not treated) revealed statistically significant differences between the combined group and group 1 (38.5\% versus $29.4 \%$; $P=0.049)$ and between group $3(40.5 \%$; $P=0.038)$-but not group $4 \quad(36.5 \%$; $P=0.177)$-and group 1 . Group 2 was not inferior to group 1 for the ACR50 response at week 24. The combination of golimumab and methotrexate allowed for significantly better results than those observed with placebo plus methotrexate in most of the other measures of efficacy, including DAS28 response/remission. The most frequent adverse events in the groups treated with golimumab plus methotrexate were nausea, upper respiratory tract infection, increased hepatic transaminases, dyspepsia, and headache [33].

After completing the 52 weeks of therapy, the patients treated with placebo plus methotrexate could switch to golimumab $50 \mathrm{mg}$ plus methotrexate, methotrexate and corticosteroid use could be adjusted, and a single change in golimumab dose (from 50 to $100 \mathrm{mg}$ or from 100 to $50 \mathrm{mg}$ ) was permitted. The 5-year follow-up was completed by 402 (66.1\%). At week 256,84.3\% of patients had a ACR20 response, 93.9\% a EULAR DAS28-CRP response, and $80.6 \%$ a $\geq 0.25$ improvement in the HAQ-DI. Among the patients treated with golimumab plus methotrexate, $64 \%$ did not show radiographic progression. The most common adverse events were upper airway infections (29.4\%), nausea (19.6\%), bronchitis (16.6\%), and increased alanine aminotransferase (16.1\%) [34].

The multicenter, randomized, placebocontrolled, double-blind, phase III trial GOFORWARD (GOlimumab FOR subjects With Active RA Despite methotrexate) aimed at evaluating the efficacy and safety of golimumab in adult patients with active moderate/severe RA treated with methotrexate ( $\geq 15 \mathrm{mg} /$ weekly) and naïve to anti-TNF, rituximab, natalizumab, and cytotoxic agents [35-38]. The 444 patients were enrolled in 4 groups: placebo plus methotrexate (group 1, $n=133)$, golimumab $100 \mathrm{mg} / \mathrm{month}$ plus placebo (group 2, $n=133$ ), golimumab SC $50 \mathrm{mg} / \mathrm{month}$ plus methotrexate (group 3, $n=89$ ) and golimumab $100 \mathrm{mg} / \mathrm{month}$ plus methotrexate (group 4, $n=89$ ). Co-primary endpoints were the proportion of patients with an ACR20 response at week 14 and the improvement from baseline in the HAQ-DI score at week 24 . The main secondary endpoints were DAS28 (CRP) response at week 14, ACR20 response at week 24 and the improvement from baseline in the HAQ-DI score at week 14.

At week 14, a significantly higher proportion of patients treated with $50 \mathrm{mg}(55.1 \%)$ and $100 \mathrm{mg}(56.2 \%)$ golimumab plus methotrexate achieved an ACR20 response compared with the placebo group $(33.1 \% ; P=0.001)$. Moreover, at 
week 24 the median improvement in the HAQDI score was significantly greater among patients treated with golimumab plus methotrexate $(-0.44)$ as compared with those treated golimumab or methotrexate used as a monotherapy $(-0.13, P<0.001)$. As for the secondary endpoints, the percentages of patients with ACR50 and ACR70 response at week 14, and ACR20, ACR50, and ACR70 at week 24 were significantly higher for patients treated with golimumab plus methotrexate as compared with placebo plus methotrexate ( $P<0.05$ for all comparisons). At week 16 , the proportion of patients with adverse events was $60.9 \%$ in group $1,63.2 \%$ in group $2,68.5 \%$ in group 3, and $69.7 \%$ in group 4 . Severe adverse events were reported in $2.3 \%, 3.8 \%, 5.6 \%$ and $9.0 \%$ of patients, respectively [35].

The result of the 52 week follow-up of the GO-FORWARD trial showed an ACR20 improvement of $44 \%$ in group 1, $45 \%$ in group 2, 64\% in group 3, and 58\% in group 4 . These results demonstrate that the response rates achieved with golimumab at week 24 are maintained to 52 [36].

Recently, Keystone et al. also published the results at 104 weeks of the GO-FORWARD trial. The clinical improvement was maintained through week $104 ; 74.7 \%$ and $71.6 \%$ of patients treated with golimumab 50 and $100 \mathrm{mg}$, respectively, attained an ACR20 response. The majority $(105 / 129 ; 88 \%)$ of patients treated with golimumab plus methotrexate who had an improvement in the HAQ-DI score $\geq 0.25$ at week 24 maintained this beneficial effect on physical function up to week 104. Patients with delayed golimumab treatment showed greater radiographic progression at week 104 (mean change score $=1.15$ ) as compared to those with early treatment with golimumab plus methotrexate (0.52). No new side effects were observed after 2 years of treatment with golimumab plus methotrexate [37].

A total of 313 patients continued treatment through week 252 (5 years) and 301 completed the safety follow-up through week 268 . After 5 years of treatment, $76.0 \%$ of all patients had an ACR20 response, $89.5 \%$ a DAS28-CRP EULAR response, and $68.5 \%$ an improvement in the HAQ-DI $\geq 0.25$. The percentage of patients retained in the study was high (70.5\%), with long-term maintenance of improvement in RA symptoms/signs and physical function after treatment with golimumab plus methotrexate [38].

\section{UPDATE ON SAFETY}

\section{Infections}

A recent study published in Arthritis Care \& Research analyzed the cases of tuberculosis that developed among the 2,210 patients treated with golimumab for 1 year in the five regulatory trials [42]. These studies permitted the recruitment of patients with latent tuberculosis at baseline, who had undergone isoniazid prophylaxis 1 month before starting the study: none of these 317 patients developed active tuberculosis during the 52 weeks of follow-up. Overall there were five cases of active tuberculosis in patients who screened negatively at baseline, all of them in patients from countries with high background rates of disease. An adequate screening program before initiating biologic therapy is very important in that it reduces the incidence of reactivation of latent tuberculosis by up to $85 \%$ [42].

\section{Malignancies}

A recent meta-analysis assessed the risk of malignancy in 29,423 RA patients treated with 
biological agents (including golimumab) in the course of 63 clinical trials of at least 6 months' duration. The use of biological drugs in this setting is not associated with a significantly increased risk of developing a malignancy as compared with other active drugs (DMARD) or placebo [43]. The meta-analysis by Le Blay et al. [44] focused on the neoplastic risk of certolizumab and golimumab in 2,710 RA patients enrolled in randomized clinical trials. Among patients treated with anti-TNF agents, 18 cases of malignancy were observed and 9 cases of nonmelanoma skin cancer (NMSC) versus 4 and 3 cases, respectively, in the control group, with an odds ratio of 1.06 for the risk of malignancy and 0.69 for that of NMSC with certolizumab and golimumab versus DMARDs. The results of this meta-analysis did not show an increased risk of any type of malignancy, although further data on the long-term use of these anti-TNF agents are required [44].

\section{UNIQUE ROUTES OF DELIVERY/ ADMINISTRATION}

Patient comfort with SC injections depends both on the formulation of the solution and the administration of the drug itself; the factors that affect tolerance are the solution volume, the strength and composition of the buffer, reactions at the injection site and the frequency of injections. The L-histidine buffer used in golimumab has proved to be less painful and better tolerated than the citrate buffer solution used in the SC formulations of other anti-TNF agents; moreover histidine buffers are no more painful than saline solution [45]. The low injection volume $(0.5 \mathrm{ml}$ per dose $)$ and the composition of golimumab solutions for injection mean that patients experience less pain at the injection site [46].
Golimumab is the first effective single-use anti-TNF agent administered subcutaneously once a month. It comes in two convenient formulations: a pre-filled, single-dose syringe or a single-dose Smartject autoinjector (pre-filled pen containing $0.5 \mathrm{ml}$ of solution, designed to ensure fast and simple delivery). The GO-MORE trial also evaluated the use of the autoinjector for the SC administration of golimumab. According to the majority of patients, the autoinjector was easy to use, and caused neither discomfort nor pain. After 6 months, many of the patients assessed for efficacy reported that they preferred to inject into the thigh $(75.2 \% ; 1,563 / 2,077)$. Over $95 \%$ of patients considered the use of the autoinjector to be safe/very safe and $92.1 \%$ were satisfied/very satisfied with the monthly frequency of self-injections. Responses did not change in the different age groups. After 6 months, the experience with the selfinjection process was rated as extremely positive and positive by $53.7 \%$ and $39.5 \%$ of patients without disability, respectively, and by $42.5 \%$ and $49.1 \%$ of those with disability [47].

\section{COST OF THERAPY}

RA, AS, and PsA have a high economic impact on the individual and on society. The annual mean total cost of RA per patient in Europe $€ 14,906$, whereas that of AS is $€ 9,374$ [48]. The mean total cost (direct plus indirect) of a patient with PsA in Italy is approximately $€ 3.000$ [49]. Discontinuation or change in therapy are common occurrences during treatment with antiTNF- $\alpha$ agents, and generally lead to a significant increase in treatment-related costs [50].

In Italy, the cost of a single $0.5 \mathrm{ml}(50 \mathrm{mg})$ pack of golimumab (1 month of treatment) is $€ 1,723.33$ (€973.18 as ex-factory price), corresponding to an annual cost of $€ 11,678.14$. These costs are virtually identical to those of the 
other treatments currently available for AS (adalimumab, etanercept) or for RA alone (abatacept and tocilizumab) [51].

An analysis by Carter [52] compared the costs of 1 year of therapy with four subcutaneously injected treatments: adalimumab, etanercept, certolizumab, and golimumab in patients affected by RA. The costs of the drugs for 1 year of therapy were comparable $(\$ 19,812$ for adalimumab, $\$ 21,940$ for certolizumab, $\$ 20,190$ for etanercept and $\$ 19,824$ for golimumab) [52]. A second analysis that simulated treatment of a cohort of 10,000 patients for 5 years estimated a cost per qualityadjusted life-year (QALY) with golimumab of $\$ 6,904$, that is, equivalent to that of other treatments (range, $\$ 6,300-\$ 6,600$ ) [53].

The use of golimumab in PsA has also been recently analyzed in a decision analysis model which simulated the clinical and economic outcomes of treatment [54]. Cost-effectiveness analysis against palliative care showed that golimumab is as cost-effective as the other alternatives taken into consideration, whereas probabilistic sensitivity analysis showed that golimumab had $50 \%$ and $89 \%$ probability of being cost-effective at willingness-to-pay thresholds of $£ 20,000$ and $£ 30,000$ per QALY [54].

Finally, a cost-effectiveness analysis on patients with severe AS demonstrated that, as compared with standard therapy, the incremental cost-effectiveness ratios (ICER) of golimumab, adalimumab, and etanercept were very similar. In addition, golimumab produced the greatest net cost reduction at a willingnessto-pay threshold of $£ 30,000$ per QALY [55].

\section{CONCLUSIONS}

Golimumab is the first anti-TNF monoclonal antibody administered subcutaneously once a month and produced with an innovative technology (cell line of mouse hybridomas created with recombinant DNA technology) that minimizes immunogenicity of the antibody after injection into the body.

Golimumab, used as a monotherapy or in combination with methotrexate (in accordance with the "therapeutic indications" reported in the summary of the product characteristics [56]), is indicated for the treatment of severeto-moderate active forms of RA, PsA, and AS not responding adequately to conventional therapy. The many large studies conducted on these populations have demonstrated that the drug is effective in improving the signs and symptoms of the disease and the physical function of the patients, even in the long term. Furthermore, golimumab has proved to have a safety profile consistent with that of other anti-TNF agents.

Finally, the use of golimumab proved to be cost-effective, simple (no loading dose is required, its two delivery systems are easy to use even by patients who may have difficulty handling normal syringes given the impact of the disease on the hands) and convenient for the patient (the once-monthly SC injection could help to minimize the impact of treatment delivery on the patient's quality of life).

\section{ACKNOWLEDGMENTS}

This manuscript has been reviewed by the medical advisors at MSD Italia S.r.l. for scientific accuracy. Professor M. Rossini is the guarantor for this article, and takes responsibility for the integrity of the work as a whole. This article does not necessarily reflect the opinions, policies, or recommendations of MSD Italia S.r.l or any of its employees. Editorial 
assistance in the preparation of this manuscript was provided by Dr. Piero Zucchi, freelance medical writer and Dr. Itala Brancaleone freelance translator. Support for this assistance was funded by MSD Italia S.r.l. No funding or sponsorship was received for this study or publication of this article.

Conflict of interest. Professor S. De Vita has received speaker fees from Bristol-Myers Squibb, Glaxo, Roche, and UCB.

Professor M. Govoni has received speaker fees from Pfizer, Abbvie, Roche, Mundipharma, and honoraria for advisory boards from Abbvie.

Professor S. Adami has received speaker fees from Amgen, MSD and Eli-Lilly and honoraria for advisory boards from MSD, Amgen and Pfizer.

Professors M. Rossini, C. Ferri, G. Paolazzi and C. Salvarani declare that they have no conflict of interest.

Compliance with ethics guidelines. This article is based on previously conducted studies, and does not involve any new studies of human or animal subjects performed by any of the authors.

Open Access. This article is distributed under the terms of the Creative Commons Attribution Noncommercial License which permits any noncommercial use, distribution, and reproduction in any medium, provided the original author(s) and the source are credited.

\section{REFERENCES}

1. Smolen JS, Landewé R, Breedveld FC, et al. EULAR recommendations for the management of rheumatoid arthritis with synthetic and biological disease-modifying antirheumatic drugs: 2013 update. Ann Rheum Dis. 2013. doi:10.1136/ annrheumdis-2013-204573.
2. Gossec L, Smolen JS, Gaujoux-Viala C, et al. European League Against Rheumatism recommendations for the management of psoriatic arthritis with pharmacological therapies. Ann Rheum Dis. 2012;71:4-12.

3. Braun J, van den Berg R, Baraliakos X, et al. 2010 update of the ASAS/EULAR recommendations for the management of ankylosing spondylitis. Ann Rheum Dis. 2011;70:896-904.

4. Van der Heijde D, Sieper J, Maksymowych WP, et al. 2010 update of the International ASAS recommendations for the use of anti-TNF agents in patients with spondyloarthritis. Ann Rheum Dis. 2011;70:905-8.

5. Chovel-Sella A, Karplus R, Sella T, Amital H. Clinical efficacy and adverse effects of golimumab in the treatment of rheumatoid arthritis. Isr Med Assoc J. 2012;14:390-4.

6. Kay J, Rahman MU. Golimumab: a novel human anti-TNF-alpha monoclonal antibody for the treatment of rheumatoid arthritis, ankylosing spondylitis, and psoriatic arthritis. Core Evid. 2009;4:159-70.

7. Lonberg N. Human monoclonal antibodies from transgenic mice. In: Chernajovsky Y, Nissim A, editors. Therapeutic antibodies. Handbook of experimental pharmacology. Berlin: Springer; 2008.

8. Shealy D, Cai A, Staquet K, et al. Characterization of golimumab, a human monoclonal antibody specific for human tumor necrosis factor alpha. MAbs. 2010;2:428-39.

9. Nelson AL, Dhimolea E, Reichert JM. Development trends for human monoclonal antibody therapeutics. Nat Rev Drug Discov. 2010;9:767-74.

10. Kay J, Matteson EL, Dasgupta B, et al. Golimumab in patients with active rheumatoid arthritis despite treatment with methotrexate: a randomized, double-blind, placebo-controlled, dose-ranging study. Arthritis Rheum. 2008;58:964-75.

11. Wagner CL, Visvanathan $S$, Elashoff $M$, et al. Markers of inflammation and bone remodelling associated with improvement in clinical response measures in psoriatic arthritis patients treated with golimumab. Ann Rheum Dis. 2013;72:83-8.

12. Kirkham BW, Wasko MC, Hsia EC, et al. Effects of golimumab, an anti-tumour necrosis factor- $\alpha$ human monoclonal antibody, on lipids and markers of inflammation. Ann Rheum Dis. 2013 Jan 7. [Epub ahead of print].

13. Zhou $H$, Jang $H$, Fleischmann $R M$, et al. Pharmacokinetics and safety of golimumab, a fully 
human anti-TNF-alpha monoclonal antibody, in subjects with rheumatoid arthritis. J Clin Pharmacol. 2007;47:383-96.

14. Zhuang $\mathrm{Y}, \mathrm{Xu} \mathrm{Z}$, Frederick B, et al. Golimumab pharmacokinetics after repeated subcutaneous and intravenous administrations in patients with rheumatoid arthritis and the effect of concomitant methotrexate: an open-label, randomized study. Clin Ther. 2012;34:77-90.

15. Simsek I, Yazici Y. Safety and clinical efficacy of golimumab in the treatment of arthritides. Drug Healthc Patient Saf. 2010;2:169-80.

16. $\mathrm{Xu} \mathrm{ZH}$, Lee $\mathrm{H}, \mathrm{Vu} \mathrm{T}$, et al. Population pharmacokinetics of golimumab in patients with ankylosing spondylitis: impact of body weight and immunogenicity. Int J Clin Pharmacol Ther. 2010;48:596-607.

17. Ling J, Lyn S, Xu Z, et al. Lack of racial differences in the pharmacokinetics of subcutaneous golimumab in healthy Japanese and Caucasian male subjects. J Clin Pharmacol. 2010;50:792-802.

18. Kavanaugh A, McInnes I, Mease $\mathrm{P}$, et al. Golimumab, a new human, tumor necrosis factor alpha antibody, administered every four weeks as a subcutaneous injection in psoriatic arthritis: twenty-four-week efficacy and safety results of a randomized, placebo-controlled study. Arthritis Rheum. 2009;60:976-86.

19. Kavanaugh A, Mease P. Treatment of psoriatic arthritis with tumor necrosis factor inhibitors: longer-term outcomes including enthesitis and dactylitis with golimumab treatment in the Longterm Extension of a Randomized, Placebocontrolled Study (GO-REVEAL). J Rheumatol Suppl. 2012;89:90-3.

20. Kavanaugh A, McInnes IB, Mease PJ, et al. Clinical efficacy, radiographic and safety findings through 2 years of golimumab treatment in patients with active psoriatic arthritis: results from a long-term extension of the randomised, placebo-controlled GO-REVEAL study. Ann Rheum Dis. 2013; 72:1777-85.

21. Kavanaugh A, McInnes IB, Krueger GG, et al. Patient reported outcomes and the association with clinical response in patients with active psoriatic arthritis treated with golimumab: findings through 2 years of the GO-REVEAL trial. Arthritis Care Res (Hoboken). 2013;65:1666-73.

22. Inman RD, Davis JC Jr, van der Heijde $\mathrm{D}$, et al. Efficacy and safety of golimumab in patients with ankylosing spondylitis: results of a randomized, double-blind, placebo-controlled, phase III trial. Arthritis Rheum. 2008;58:3402-12.
23. Deodhar A, Braun J, Inman RD, et al. Golimumab reduces sleep disturbance in patients with active ankylosing spondylitis: results from a randomized, placebo-controlled trial. Arthritis Care Res (Hoboken). 2010;62:1266-71.

24. Deodhar $A$, Braun J, Inman $\mathrm{R}$, van der Heijde $\mathrm{D}$, Zhou Y, Hsu B. Long-term safety and efficacy of golimumab in the treatment of ankylosing spondylitis: results through 5 years of the GORAISE trial. EULAR 2013, Madrid 12-15 June 2013. ABS THU0352.

25. Braun J, Deodhar A, Inman RD, et al. Golimumab administered subcutaneously every 4 weeks in ankylosing spondylitis: 104 week results of the GO-RAISE study. Ann Rheum Dis. 2012;71:661-7.

26. Braun J, Baraliakos $\mathrm{X}$, Hermann $\mathrm{KG}$, et al. Golimumab reduces spinal inflammation in ankylosing spondylitis: MRI results of the randomised, placebo-controlled GO-RAISE study. Ann Rheum Dis. 2012;71:878-84.

27. Braun J, Baraliakos X, Hermann KG, et al. The effect of two golimumab doses on radiographic progression in ankylosing spondylitis: results through 4 years of the GO-RAISE trial. Ann Rheum Dis. 2013 (Epub ahead of print).

28. Smolen JS, Kay J, Doyle MK, et al. Golimumab in patients with active rheumatoid arthritis after treatment with tumour necrosis factor alpha inhibitors (GO-AFTER study): a multicentre, randomised, double-blind, placebo-controlled, phase III trial. Lancet. 2009;374:210-21.

29. Smolen JS, Kay J, Landewé RB, et al. Golimumab in patients with active rheumatoid arthritis who have previous experience with tumour necrosis factor inhibitors: results of a long-term extension of the randomised, double-blind, placebo-controlled GOAFTER study through week 160 . Ann Rheum Dis. 2012;71:1671-9.

30. Smolen JS, Kay J, Landewé R, et al. Five year safety and efficacy of golimumab in patients with active rheumatoid arthritis despite previous anti-tumor necrosis factor therapy: final study results of the phase 3, randomized, placebo-controlled GOAFTER trial. EULAR 2013, Madrid 12-15 June 2013. ABS THU0202.

31. Combe B, Dasgupta B, Louw I, et al. Efficacy and safety of golimumab as add-on therapy to diseasemodifying antirheumatic drugs: results of the GOMORE study. Ann Rheum Dis. 2013 (Epub ahead of print).

32. Wollenhaupt J, Alonso-Ruiz A, Spieler W, et al. Efficacy and safety of add-on golimumab treatment in patients with rheumatoid arthritis receiving 
concomitant methotrexate or leflunomide. EULAR 2013, Madrid 12-15 June 2013. ABS AB0273.

33. Emery P, Fleischmann RM, Moreland LW, et al. Golimumab, a human anti-tumor necrosis factor alpha monoclonal antibody, injected subcutaneously every four weeks in methotrexatenaive patients with active rheumatoid arthritis: twenty-four-week results of a phase III, multicenter, randomized, double-blind, placebo-controlled study of golimumab before methotrexate as first-line therapy for early-onset rheumatoid arthritis. Arthritis Rheum. 2009;60:2272-83.

34. Emery P, Fleischmann RM, Strusberg I, et al. Fiveyear safety and efficacy of golimumab in methotrexate-naïve patients with rheumatoid arthritis: final study results of the phase 3, randomized, placebo-controlled GO-BEFORE trial. EULAR 2013, Madrid 12-15 June 2013. ABS FRI0178.

35. Keystone EC, Genovese MC, Klareskog L, et al. Golimumab, a human antibody to tumour necrosis factor-alpha given by monthly subcutaneous injections, in active rheumatoid arthritis despite methotrexate therapy: the GO-FORWARD Study. Ann Rheum Dis. 2009;68:789-96.

36. Keystone E, Genovese MC, Klareskog L, et al. Golimumab in patients with active rheumatoid arthritis despite methotrexate therapy: 52 week results of the GO-FORWARD study. Ann Rheum Dis. 2010;69:1129-35.

37. Keystone EC, Genovese MC, Hall S, et al. Golimumab in patients with active rheumatoid arthritis despite methotrexate therapy: results through 2 years of the GO-FORWARD study extension. J Rheumatol. 2013;40:1097-103.

38. Keystone E, Genovese MC, Hall S, et al. Five-year safety and efficacy of golimumab in patients with active rheumatoid arthritis despite prior treatment with methotrexate: final study results of the phase 3 , randomized placebo-controlled GO-FORWARD trial. EULAR 2013, Madrid 12-15 June 2013. ABS AB0267.

39. Wagner C, Visvanathan S, Braun J, et al. Serum markers associated with clinical improvement in patients with ankylosing spondylitis treated with golimumab. Ann Rheum Dis. 2012;71:674-80.

40. Durez P, Pavelka K, Lazaro M, et al. Remission rates during golimumab treatment for rheumatoid arthritis are associated with differences in baseline disease states across geographic regions in the GOMORE study. EULAR 2013, Madrid 12-15 June 2013. ABS AB0281.

41. Combe B, Veale D, Burgos-Vargas R, et al. Comprehensive disease control with golimumab in patients with rheumatoid arthritis. EULAR 2013, Madrid 12-15 June 2013. ABS THU0178.

42. Hsia EC, Cush JJ, Matteson EL, et al. Comprehensive tuberculosis screening program in patients with inflammatory arthritides treated with golimumab, a human anti-tumor necrosis factor antibody, in phase III clinical trials. Arthritis Care Res (Hoboken). 2013;65:309-13.

43. Lopez-Olivo MA, Tayar JH, Martinez-Lopez JA, et al. Risk of malignancies in patients with rheumatoid arthritis treated with biologic therapy: a metaanalysis. JAMA. 2012;308:898-908.

44. Le Blay P, Mouterde G, Barnetche T, Morel J, Combe B. Short-term risk of total malignancy and nonmelanoma skin cancers with certolizumab and golimumab in patients with rheumatoid arthritis: metaanalysis of randomized controlled trials. J Rheumatol. 2012;39:712-5.

45. Laursen T, Hansen B, Fisker S. Pain perception after subcutaneous injections of media containing different buffers. Basic Clin Pharmacol Toxicol. 2006;98:218-21.

46. Jørgensen JT, Rømsing J, Rasmussen M, MøllerSonnergaard J, Vang L, Musaeus L. Pain assessment of subcutaneous injections. Ann Pharmacother. 1996;30:729-32.

47. Schulze-Koops H, Giacomelli R, Samborski W, et al. Patient evaluations of autoinjectors for delivery of subcutaneous golimumab for treatment of rheumatoid arthritis. EULAR 2013, Madrid 12-15 June 2013. ABS THU0198.

48. Franke LC, Ament AJ, van de Laar MA, Boonen A, Severens JL. Cost-of-illness of rheumatoid arthritis and ankylosing spondylitis. Clin Exp Rheumatol. 2009;27(4 Suppl 55):S118-23.

49. Olivieri I, de Portu S, Salvarani C, et al. The psoriatic arthritis cost evaluation study: a cost-of-illness study on tumour necrosis factor inhibitors in psoriatic arthritis patients with inadequate response to conventional therapy. Rheumatology (Oxford). 2008;47:1664-70.

50. Tang B, Rahman M, Meissner B, Dabbous O1, Thompson HC. Association between switching patterns among anti-tumor necrosis factors (antiTNFs) and the healthcare costs in the treatment of rheumatoid arthritis [Poster]. ISPOR 10th Annual European Congress; Dublin, Ireland, October 20-23, 2007.

51. Italian Medicines Agency. http://www. agenziafarmaco.gov.it/it/content/liste-di-trasparenzae-rimborsabilit\%C3\%A0 (last accessed November 20, 2013). 
52. Carter C, Schmeichel-Mueller C, McKenzie RS, Piech CT. Cost analysis of recently approved and older anti-TNF biologic agents used In rheumatoid arthritis. ISPOR 15th annual international meeting, Atlanta, May 15-19, 2010. Poster PMS7.

53. Nguyen CM, Bounthavong $M$, Mendes MA, et al. Cost utility of tumour necrosis factor- $\alpha$ inhibitors for rheumatoid arthritis: an application of Bayesian methods for evidence synthesis in a Markov model. Pharmacoeconomics. 2012;30:575-93.

54. Cummins E, Asseburg C, Prasad M, Buchanan J, Punekar YS. Cost effectiveness of golimumab for the treatment of active psoriatic arthritis. Eur J Health Econ. 2012;13:801-9.
55. Farrell J, Muszbek N, Sheppard O, Chaudhary M, Naci H, Kachroo S. The long term cost-effectiveness of golimumab for the treatment of severe, active ankylosing spondylitis in adults who have responded inadequately to conventional therapy. ISPOR 14th annual European congress, Madrid, November 5-8, 2011. Poster PMS47.

56. Simponi ${ }^{\circledR}$ (golimumab). Summary of Product Characteristics (SPC). http://www.ema.europa. eu/docs/en_GB/document_library/EPAR_Product_ Information/human/000992/WC500052368.pdf (last accessed: 06/08/2013). 